\title{
How to Improve Customer Engagement: A Comparison of Playing Games on Personal Computers and on Mobile Phones
}

\author{
Kai Kang ${ }^{1}$, Jinxuan $\mathrm{Lu}^{2}$, Lingyun $\mathrm{Guo}^{3}$ and Jing Zhao ${ }^{4}$ \\ ${ }^{1}$ Hebei University of Technology, School of Economics and Management, Tianjin, China, 61798608@qq.com \\ ${ }^{2}$ Hebei University of Technology, School of Economics and Management, Tianjin, China, \\ 348703099@qq.com \\ ${ }^{3}$ Hebei University of Technology, School of Economics and Management, Tianjin, China, \\ guolingyun1111@sina.cn \\ ${ }^{4}$ Hebei University of Technology, School of Economics and Management, Tianjin, China, 421396061@qq.com
}

Received 13 December 2018; received in revised form 6 June 2019; accepted 7 June 2019

\begin{abstract}
The popularity of multiplayer online battle arena games is closely linked to customer engagement. The purpose is to investigate the influences that individual motivators and environmental antecedents have upon customer engagement and continuous playing games intention, and compare the impacts between playing Multiplayer online battle arena games on personal computers and on mobile phones. A Triadic reciprocal determinism framework was developed to explain the relationship among individual motivator (flow experience), environmental antecedents (technical features and social interaction), individual behavior (continuous playing games intention), and customer engagement within multiplayer online battle arena gaming settings. Altogether 531 questionnaires from multiplayer online battle arena players were collected. Structural equation modeling with Smart-partial least squares was used to evaluate the research model. The findings suggest that the influence of flow experience on customer engagement in personal computers gaming is more significant than that in mobile gaming, while the effects of perceived ease of use and offline social interaction on customer engagement in mobile gaming are comparatively higher. This study indicates the importance of flow experience, perceived control, perceived ease of use, and social interaction in the Multiplayer online battle arena gaming development and the prosperity for better customers engaged, and to enhance customer experience.
\end{abstract}

Keywords: Customer engagement, Flow experience, Perceived control, Perceived ease of use, Social interaction, Triadic reciprocal determinism, Multiplayer online battle arena (MOBA) games 


\section{Introduction}

With the current development of information technology, video gaming has become one of the most popular recreational activities worldwide [63]. Multiplayer Online Battle Arena (MOBA) games have thus gained immense popularity from gamers [59]. For example, League of Legends (LOL) and Arena of Valor are both very popular MOBA games in China. The former has more than 100 million active users each month (site 1), and the latter becomes one of the most downloaded mobile games in the world (site 2). A recent research showed that Arena of Valor had gained 200 million users, earning CN¥ 3 billion each month in China alone (site3).

Although the MOBA game industry has enormous potential in market, with a large number of alternative products, customers can easily jump from one game to another, resulting in cut-throat competitions in the MOBA game industry. Thus, in order to enhance competitive advantages, online game developers and publishers are looking for new ways, which can provide players with the best game experience, and trying to build long relationships with customers [38]. It is worth noting that MOBA games provide customers with a highly engaging environment. While playing, gamers can communicate with other teammates/competitors by using personal computers (PC), mobile phones, or tablet PCs offline or online. They may transfer real-life social relationships into task cooperation and communication in the games. For the reasons above, MOBA games are a source of entertainment and leisure to game players [27]. As these games are immersive and interactive, players can often lose track of time, and winning such games brings a sense of accomplishment. Owing to these features, most of operations and marketing strategies recently are proposed to focus on how to improve the gamers engagement to specific game activities in the online game field. Although customer engagement is rarely studied in the game field, it has attracted the attentions of many marketing scholars, who had pointed out that it can enhance firm performance, create value and bring competitive advantage for the company [1], [13], [56]. Therefore, we attempt to introduce customer engagement into the MOBA game field to explore how to improve customer engagement in game playing.

In the extant literature, some researchers have focused on the flow experience of games, assuming that it enhances customer loyalty, satisfaction, and the desire to continue gaming [10], [39], [57]. Other scholars have studied the game technology itself, inferring that easy operability and aesthetics affect customer perception [5], [62], [65]. Moreover, some scholars have explored the influence of social interaction on playing online games, noting its positive relationship with players' continuous playing games intention [17], [51]. In summary, we note that customer experience, game technology, and social interaction are important in the study of customer engagement in MOBA games. However, few models have combined these factors. According to Triadic reciprocal determinism, individual factors, environmental antecedents, and personal behaviors are interconnected and influenced by each other [37]. The theory has been widely applied and extended in SNS marketing research [24]. In the meantime, the case of Arena of Valor illustrates that players' perception of experience may be different, influenced by game technology and social interaction, which may facilitate various levels of engagement. Therefore, it is the satisfaction of a distinct individual experience, the strong perception of game technology, and social interaction that lead to player engagement. Thus, we see flow experience as an individual factor, while the technical features of games and social interactions as environmental factors. The individual and environmental factors are antecedents of customer engagement, which in turn, affect players' continuous playing games intention. This constitutes our first research purpose. In the research, the application of Triadic reciprocal determinism is comparatively earlier in the field of MOBA games, which enriches the driving mechanism of consumer engagement.

In addition, most extant studies are based on only one type of client terminal, such as PCs [19], [26], [29], mobile phones [41], [43] or tablet PCs [52]. However, it is worth exploring whether the conclusions of previous research can be extended to different research backgrounds. Will playing MOBA games on different client terminals have different effects among these three aspects? This is our second research purpose. We compared the effect of driving factors on consumer engagement between the PC game and the mobile game respectively, which provide personalized marketing strategies for firms to design game products more specifically.

To offset the deficiency of these two aspects, and in the view of Triadic reciprocal determinism and customer engagement, we developed a framework to explain the relationship of individual motivator (flow experience), environmental factors (technical features and social interaction), customer engagement, and individual behavior (continuous playing games intention) in the MOBA gaming setting. Particularly, we verified the proposed model in an empirical research on two MOBA games. Our study explains how individual and environmental factors influence customer engagement and personal behavior. The findings will provide a more specific and contextualized understanding of Triadic reciprocal determinism. 


\section{Theoretical Background and Research Hypotheses}

In this section we describe the theoretical basis and relevant literature for Triadic reciprocal determinism, customer engagement and some factors. Also, we present the main concepts and expected links behind the suggested hypotheses to be tested in the research model.

\subsection{Triadic Reciprocal Determinism}

Triadic reciprocal determinism was proposed by Bandura based on the study of the Levin model [2]. The theory points out that behavior, individual factors, and environmental elements are interconnected and influenced by each other [3], [24], [45]. Among them, both individual factors and environment elements have impacts on behavior. Thus, all the three interact with each other, forming a triangular relationship [4]. The views of Triadic reciprocal determinism embody the following three connotations. First, behavior is affected by both individual and environmental factors. Second, individual factors play a leading role in the Triadic reciprocal determinism. Individuals may consciously choose the environment where behavior occurs, and some other opinions pointed out that environmental factors depends on individual cognitive processes. Third, the circularity of the Triadic reciprocal determinism gives a chance to develop the individual's cognitive process. Most of the existing researches on social cognitive theory focus on the behavior and psychological characteristics of members in real groups, including communities, enterprises, and educational groups [38]. With the deepening and expansion of research, a number of scholars believe that the behavioral and psychological research of customers in virtual network environment also applies to Triadic reciprocal determinism. For example, based on the Triadic reciprocal determinism, Lu and Lee [50] studied the impact of cognitive needs, social marketing, and blog quality on blog viscous behavior. Kim, Lee, and Elias [45] applied social cognition theory to social networks to identify individual factors (self-efficacy and outcome expectations) and environmental factors (social tie strength and social network size) and empirically demonstrated that they alternatively affect information sharing behavior. Hu, Zhang, and Luo [37] explored the impact of factors such as self-control and community interaction on user engagement in video sharing community behavior. However, from the current research status, the application of Triadic reciprocal determinism to the field of online games is still relatively rare.

In summary, by employing the Triadic reciprocal determinism, it is beneficial to deeply explore the mechanism of MOBA game players' behavior from the two dimensions of entertainment environment and individual factors. We use the Triadic reciprocal determinism as the fundamental theory to develop our study for several reasons. First, it can serve as an overarching framework to explore why a user engages in MOBA games. Second, Triadic reciprocal determinism emphasizes the complicated and dynamic mechanism of reciprocal influence, which offers us the theoretical foundation to examine the interaction effect of behavior, individual facts, and environmental factors. Thus, we recognize the technical features and social interaction in MOBA gaming as environmental factors, individual experience as individual factors, and continuous playing games intention as individual behavior.

\subsection{Customer Engagement}

It is currently impossible to imagine online life without engaged and active users, which MOBA games must accomplish in order to develop further [68], [70]. Bowden et al. and Zhang et al. defined customer engagement as a psychological process of building brand relationships based on cognition and emotion [7], [8], [76]. Brodie et al. [7] defined customer engagement as a dynamic and repetitive interaction process wherein customers and enterprises jointly create experiences in specific situations. They clearly stated that customer engagement included three aspects, namely, cognition, emotion, and behavior. While some scholars studied customer engagement as a behavioral factor, Van Doorn et al. [69] believed that customer engagement behavior is driven by motivation, beyond purchase behavior, including word-of-mouth publicity, recommendation products, and so on. Guo et al. [25] studied three aspects of customer engagement behavior. Based on previous research, we define customer engagement as a behavioral factor that emerges when playing MOBA games, leading to players' intention to keep playing games [9]. Cheung et al. [14] proposed a research model to examine why game players actively engage in playing online games, and it can contribute to the sales of online games. Huang et al. [40] explored the impact of customer engagement on player's purchase intention of social network games, proving a positive relationship between the two aspects. Therefore, we try to study the impact of customer engagement on continuous playing games intention. We thus propose:

\section{H1: Customer engagement is positively related to continuous playing games intention.}

\subsection{Individual Factor: Flow Experience}

Numerous studies show that flow experience is the most important dimension of online gaming experience [36], [41], [65], [66]. Csikszentmihalyi first proposed flow experience, assuming that it referred to the overall feeling of an individual's complete engagement in an activity [20]. When in a state of flow experience, individuals deeply indulge in their chosen activity, feel happy, and experience time flying. Flow experience has been studied in the context of information technologies and regarded as useful in understanding consumer behavior [36], [69]. Chou and Ting [18] first applied flow experience in the study of online games. Chang [11] revealed the importance of flow experience, 
which played a mediating role, producing indirect effects in predicting Social Network Games (SNGs) continuance in his model. Harmat et al. [30] concluded that flow experience is the subjective experience of effortless attention, reduced self-awareness, and enjoyment that typically occurs during optimal task performance when playing computer games. Therefore, we infer that flow experience in playing MOBA games may produce a long-term preference for customer engagement. We thus propose:

\section{H2: Flow experience is positively related to customer engagement}

\subsection{Environmental Factors: The Technical Features and Social Interaction}

There are two important factors in the technical features, perceived control, and perceived ease of use. In social relationships, numerous scholars have empirically supported the critical nature of social interaction. We thus identify them as environmental factors.

Perceived control was first introduced by Csikszentmihalyi. He defined perceived control as "the user perception and behavior of how challenging it is to do a given activity and how skillful the user is when doing that activity" [20]. Previous studies showed that perceived control is a core factor in determining perceived usability and enjoyment of specific technologies and services [54], [70]. Koufaris [49] noted the positive influence of perceived control on the online consumer behavior, especially their loyalty to websites. In the current research, perceived control is defined as "the users' perception of how challenging it is to play online games and how skillful the user is when playing the game" [58]. Wang [71] verified that perceived control of the game process positively influences player's intention to play massively multiplayer online games (MMOGs). In the MOBA gaming setting, perceived control means that the game can be easier and more enjoyable to control. We thus propose:

\section{H3a: Perceived control is positively related to customer engagement.}

Extensive research has shown that perceived ease of use is an important factor influencing user acceptance and user behavior of information technologies [61]. Perceived ease of use refers to "the degree to which a person believes that using a particular system would be free of effort" [48]. Davis [21] claimed that an application/system perceived to be easier to use than another is more likely to be accepted by users. Similarly, Zeithaml et al. [75] stated that the degree to which an innovation is easy to be understood or used could be considered as perceived ease of use. According to Zhao et al. [77], the intensity of an individual's intention to use a technology can be explained jointly by their perception of the technology's usefulness and ease of use. Wu and Chen [72] pointed that, where technology usage requires less effort to perform a task, the perceived ease of use is likely to be higher, which in turn, leads to a higher likelihood of adoption for use. We thus propose:

\section{H3b: Perceived ease of use is positively related to customer engagement.}

Research on interactive behavior in online games was first developed from the perspective of sociology. Hoffman and Novak proposed personal interaction targeting the computer mediated environment (CME). Social interaction refers to the way in which gamers communicate with each other using a PC or mobile phone as medium [34], [64]. Choi and Kim [15] noted that players' participation in online games is based on social interaction, influencing the player's loyalty to the game. Yee [74] conducted a combined analysis of the motivation, emotional involvement, and relationship in the online game players, concluding that online games could affect personal relationships in a player's real life. Computermediated communication (CMC) features enable players to engage in social interaction with other players before, during, and after playing games [47]. Trepte et al. [67] showed that online gaming might result in strong social ties if gamers engage in online activities beyond the game and extend these with offline activities. Recently, Kim and Kim [46] examined the development of the engagement intention of online game community members based on social relational bonds. Hsu and Lin [35] have studied the relationships between online/offline satisfaction and loyalty. Hence, we try to explore the impact of online and offline social interaction in playing MOBA games on customer engagement. Thus, we hypothesize:

H4a: Online social interaction is positively related to customer engagement.

H4b: Offline social interaction is positively related to customer engagement.

\subsection{Influence of Devices: PC and Mobile Phone}

Most extant studies are based on only one type of client terminal, such as PCs [19], [26], [29], mobile phones [41], [42], [43] or tablet PCs [52]. However, it is worth exploring whether the conclusions of previous research can be extended to different research backgrounds. Green and Bavelier [23] found that playing PC games increases a player's spatial awareness. Park, Baek, Ohm, and Chang [58] indicated that mobile-social network games provide an opportunity for communication between players to meet their relationship needs, allowing them to enjoy the game and generate the intention to play. User's demands for mobile games is currently high and mobile games have the following characteristics: popular, skilled, flowing, entertaining, convenient, and disseminate. Park and Kim [59] noted that simple 
game mechanics, ease of learning, successful results with less work, and short-term nature are important elements for mobile phone games, unlike in PC games, which require mouse and keyboard control.

How do players feel when playing MOBA games on different client terminals? Will it cause different effects among these three aspects? The MOBA gaming experience on PCs and mobile phones may differ [32]. By comparing the characteristics of PC games and mobile games, we investigate our hypotheses-whether playing MOBA games on different devices will produce different results. Thus, we conduct a comparative study to explore this problem. Based on Triadic reciprocal determinism and the discussion above, we construct our research model in Figure 1.

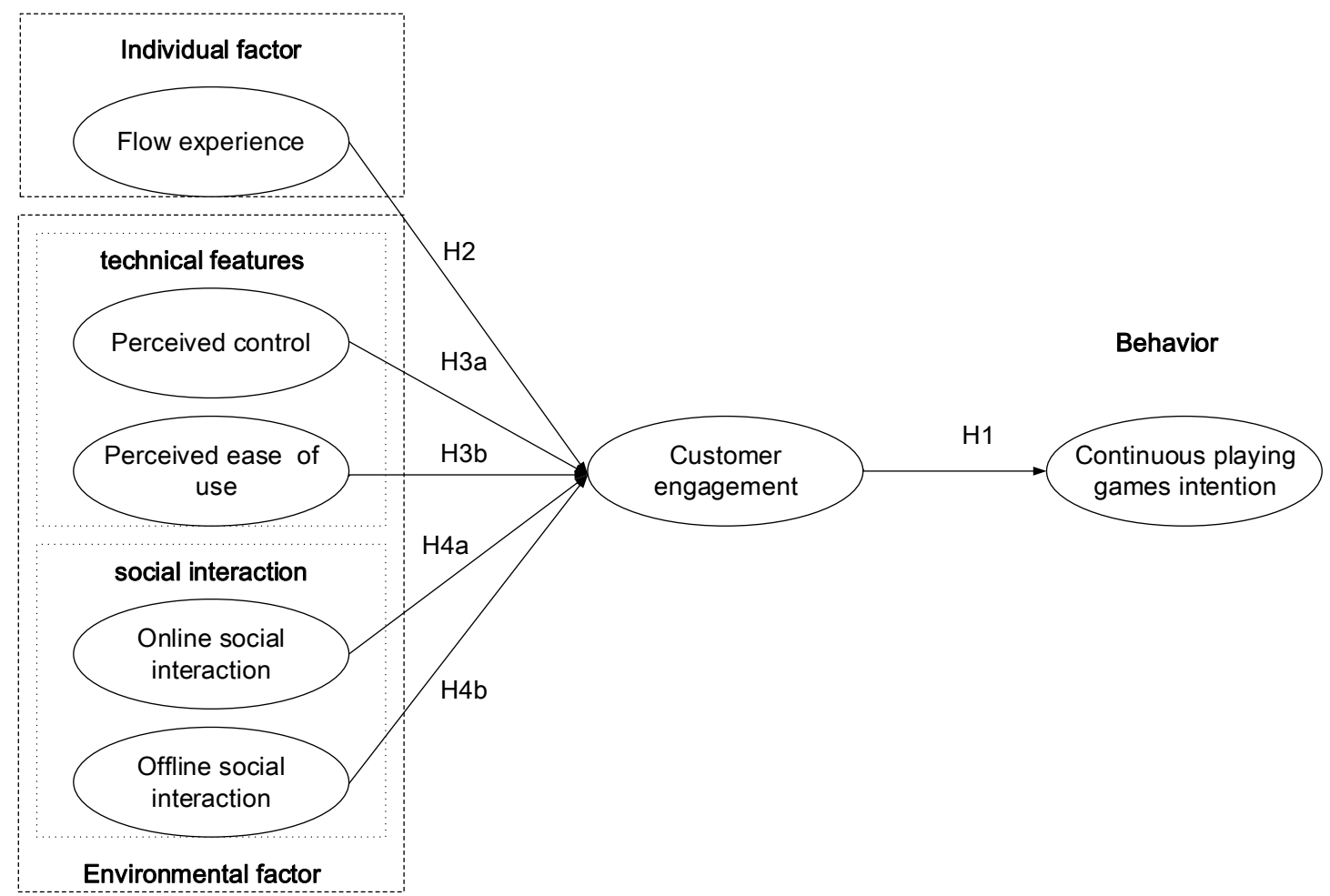

Figure 1: Proposed research model

\section{Research Method}

In order to test our proposed framework and hypotheses, we implemented an online survey among players playing LOL and Arena of Valor in China. A questionnaire based on extant literature and current study context was constructed. Then, we analyzed the obtained data using Smart-PLS 2.0.

\subsection{Measures}

We generated measurement items from previous studies and adapted them to our study to generate our questions (see Appendix A). The flow experience was adapted from Chang and Zhu [12] and Herrando et al. [33]; the scales of perceived control and perceived ease of use were derived from Park et al. [58]. The measurement of online social interaction and offline social interaction were modified with reference to the scales of Zhong [78]; customer engagement measures were derived from Guo et al. [24]; and the continuous playing games intention items were from $\mathrm{Hu}$ et al. [38]. All measures were rated on a seven-point Likert scale (1 stands for strongly disagree and 7 stands for strongly agree). In order to guarantee the adequacy and clarity of each question, we invited three experts and two game players to review the questionnaire, modifying the format, wording and fuzzy expression to support the content effectiveness of the questionnaire. To purify and validate these measurements, we conducted predictive test with 98 gamers to assess the overall interpretability and clarity of the survey questions.

\subsection{Data Collection}

We chose two different MOBA games, LOL and Arena of Valor, as representative of PC games and mobile games. Released in 2011, LOL has become one of the most popular MOBA games in China and the world. LOL is a DOTA (Defense of The Ancient)-based online PC game developed by Riot Games in the US, operated by Tencent Games in mainland China. The game has hundreds of individual heroes and special training systems. Every year, LOL organizes 
three world-class events, namely, Seasons Championship, Global Finals, and All Star All-Star Game, which attract millions of fans. Arena of Valor was launched in 2015, which is a MOBA mobile game run by Tencent Games. It won the best electronic competition game in 2015. The battlefield of Arena of Valor is the mobile phone, allowing players to compete conveniently regardless of time and place, as long as they participate in the fight. Owing to the popularity of these MOBA games, and their distinct playing devices, we selected them as appropriate contexts for our investigation.

Before filling out the questionnaire, we asked a question to screen out valid users (Have you ever played Arena of Valor or League of Legends before?). Then we recruited two exclusive participants and asked them the following questions to extract the questionnaires of two types of gamers for later analysis:

What kind of Multiplayer Online Battle Arena Games and with which kind of device have you played recently?

A. League of Legends with computer.

B. Arena of Valor with mobile phone.

Our research was carried out using Sojump (site 4), China's most popular online survey tool. Sojump has more than 2.6 million users across mainland China and offers point rewards for valid questionnaire responses. We collected questionnaire responses between June and September 2017. Ultimately, 143 questionnaires were declared invalid, as they were either blank, completed in less than the time baseline (one hundred seconds), or gave incoherent answers to similar questions. In total, 531 ( $\mathrm{LOL}, \mathrm{N}=301$; Arena of Valor, $\mathrm{N}=230$ ) valid samples were obtained. The demographics of the respondents surveyed are shown in Table 1.

Table 1: Demographic characteristics $(n=531)$

\begin{tabular}{|c|c|c|c|c|c|c|c|}
\hline \multirow{2}{*}{\multicolumn{2}{|c|}{ Demographic profile }} & \multicolumn{2}{|c|}{ LOL (N = 301) } & \multicolumn{2}{|c|}{$\begin{array}{l}\text { Arena of Valor }(\mathrm{N}= \\
230)\end{array}$} & \multicolumn{2}{|c|}{ Full samples $(\mathrm{N}=531)$} \\
\hline & & \multirow{2}{*}{$\begin{array}{l}\begin{array}{l}\text { Numbe } \\
\text { rs }\end{array} \\
179 \\
\end{array}$} & \multirow{2}{*}{$\begin{array}{l}\text { Percentage } \\
59.47 \% \\
\end{array}$} & \multirow{2}{*}{$\begin{array}{l}\text { Numbers } \\
128 \\
\end{array}$} & \multirow{2}{*}{$\begin{array}{l}\text { Percentag } \\
\text { e } \\
55.65 \%\end{array}$} & \multirow{2}{*}{$\begin{array}{l}\begin{array}{l}\text { Number } \\
\text { s }\end{array} \\
307 \\
\end{array}$} & \multirow{2}{*}{$\begin{array}{l}\begin{array}{l}\text { Percentag } \\
\text { e }\end{array} \\
57.82 \%\end{array}$} \\
\hline & Male & & & & & & \\
\hline Gender & Female & 122 & $40.53 \%$ & 102 & $44.35 \%$ & 224 & $42.18 \%$ \\
\hline \multirow{4}{*}{ Age } & $<18$ & 58 & $19.27 \%$ & 77 & $33.48 \%$ & 135 & $25.42 \%$ \\
\hline & $18-25$ & 93 & $30.90 \%$ & 86 & $37.39 \%$ & 179 & $33.71 \%$ \\
\hline & $25-35$ & 105 & $34.88 \%$ & 55 & $23.91 \%$ & 160 & $30.13 \%$ \\
\hline & $>35$ & 45 & $14.95 \%$ & 12 & $5.22 \%$ & 57 & $10.73 \%$ \\
\hline \multirow{3}{*}{ Education } & $\begin{array}{l}\text { High School Or } \\
\text { below }\end{array}$ & 32 & $10.63 \%$ & 84 & $36.52 \%$ & 116 & $21.85 \%$ \\
\hline & College & 187 & $62.13 \%$ & 92 & $40 \%$ & 279 & $52.54 \%$ \\
\hline & $\begin{array}{l}\text { Post Graduate } \\
\text { Or above }\end{array}$ & 82 & $27.24 \%$ & 54 & $23.48 \%$ & 136 & $25.61 \%$ \\
\hline \multirow{4}{*}{$\begin{array}{l}\text { Length of } \\
\text { playing }\end{array}$} & $<3$ month & 29 & $9.63 \%$ & 61 & $26.52 \%$ & 90 & $16.95 \%$ \\
\hline & 3-6 months & 71 & $23.59 \%$ & 92 & $40 \%$ & 163 & $30.70 \%$ \\
\hline & 6-12months & 45 & $14.95 \%$ & 44 & $19.13 \%$ & 89 & $16.76 \%$ \\
\hline & $>1$ year & 156 & $51.83 \%$ & 33 & $14.35 \%$ & 189 & $35.59 \%$ \\
\hline
\end{tabular}

\section{Data Analysis and Results}

In this section, data analysis and results are provided.

\subsection{Reliability and Validity}

We examine the reliability and validity of our measures for the full sample $(\mathrm{N}=531)$, LOL sample $(\mathrm{N}=301)$ and Arena of Valor sample $(N=230)$ separately. Reliability is tested using Cronbach's Alpha $(\alpha)$ and composite reliability $(C R)$. As shown in Table 2, Cronbach's $\alpha$ of all constructs range from 0.67 to 0.87 , which is above 0.6 , demonstrating good reliability [58]. The $C R$ range is $0.82-0.91$, indicating a satisfactory level of reliability [16]. All factor loadings are higher than 0.6, and AVEs are above 0.5, which indicate good convergent validity. Table 3 suggests that the square roots of AVEs (on the diagonal of the matrix) are larger than the inter-construct correlations, indicating adequate discriminant validity [22].

Moreover, we examine the measurement models for the sub-samples, adopting the same procedures and assessment criteria. The results are shown in tables 4,5 , and 6 . Compared to full samples, the results of reliability and validity are achieved. 
Table 2: Reliability and convergent validity analysis for the full sample $(\mathrm{N}=531)$

\begin{tabular}{|c|c|c|c|c|c|}
\hline Constructs & Items & $\begin{array}{l}\text { Factor } \\
\text { loading }\end{array}$ & AVE & $\begin{array}{l}\text { Composite } \\
\text { Reliability } \\
\end{array}$ & $\begin{array}{l}\text { Cronbach's } \\
\text { Alpha }\end{array}$ \\
\hline \multirow{4}{*}{ Flow experience } & FE1 & 0.82 & \multirow{4}{*}{0.72} & \multirow{4}{*}{0.91} & \multirow{4}{*}{0.87} \\
\hline & FE2 & 0.87 & & & \\
\hline & FE3 & 0.85 & & & \\
\hline & FE4 & 0.86 & & & \\
\hline \multirow{3}{*}{ Perceived control } & PC1 & 0.77 & \multirow{3}{*}{0.61} & \multirow{3}{*}{0.83} & \multirow{3}{*}{0.68} \\
\hline & PC2 & 0.78 & & & \\
\hline & PC3 & 0.79 & & & \\
\hline \multirow{3}{*}{ Perceived ease of use } & PEU1 & 0.76 & \multirow{3}{*}{0.60} & \multirow{3}{*}{0.82} & \multirow{3}{*}{0.67} \\
\hline & PEU2 & 0.76 & & & \\
\hline & PEU3 & 0.80 & & & \\
\hline \multirow{3}{*}{ Online social Interaction } & ON1 & 0.81 & \multirow{3}{*}{0.62} & \multirow{3}{*}{0.83} & \multirow{3}{*}{0.70} \\
\hline & ON2 & 0.73 & & & \\
\hline & ON3 & 0.82 & & & \\
\hline \multirow{3}{*}{ Offline social Interaction } & OFF1 & 0.87 & \multirow{3}{*}{0.74} & \multirow{3}{*}{0.90} & \multirow{3}{*}{0.82} \\
\hline & OFF2 & 0.86 & & & \\
\hline & OFF3 & 0.85 & & & \\
\hline \multirow{4}{*}{ Customer engagement } & CE1 & 0.84 & \multirow{4}{*}{0.63} & \multirow{4}{*}{0.87} & \multirow{4}{*}{0.80} \\
\hline & CE2 & 0.85 & & & \\
\hline & CE3 & 0.75 & & & \\
\hline & CE4 & 0.73 & & & \\
\hline \multirow{2}{*}{$\begin{array}{l}\text { Continuous playing } \\
\text { games intention }\end{array}$} & $\mathrm{Cl} 1$ & 0.87 & \multirow{2}{*}{0.78} & \multirow{2}{*}{0.88} & \multirow{2}{*}{0.72} \\
\hline & $\mathrm{Cl} 2$ & 0.89 & & & \\
\hline
\end{tabular}

Table 3: Discriminant validity analysis for the full sample $(\mathrm{N}=531)$

\begin{tabular}{|l|l|l|l|l|l|l|l|}
\hline Constructs & FE & PC & PEU & ON & OFF & CE & CI \\
\hline FE & 0.85 & & & & & & \\
\hline PC & 0.46 & 0.78 & & & & & \\
\hline PEU & 0.41 & 0.59 & 0.77 & & & & \\
\hline ON & 0.35 & 0.47 & 0.46 & 0.79 & & & \\
\hline OFF & 0.60 & 0.51 & 0.48 & 0.40 & 0.86 & & \\
\hline CE & 0.67 & 0.58 & 0.56 & 0.48 & 0.67 & 0.79 & \\
\hline Cl & 0.47 & 0.55 & 0.54 & 0.39 & 0.56 & 0.56 & 0.88 \\
\hline
\end{tabular}

Note : Diagonal elements show the square root of average variance extracted (AVE). Other elements are latent variable correlating coefficients.

Table 4: Reliability and convergent validity analysis for sub-samples: LOL $(N=301)$ vs. Arena of Valor $(N=230)$

\begin{tabular}{|c|c|c|c|c|c|c|c|c|c|}
\hline \multirow[b]{2}{*}{ Constructs } & \multirow[b]{2}{*}{ Items } & \multicolumn{4}{|c|}{ LOL $(N=301)$} & \multicolumn{4}{|c|}{ Arena of Valor $(\mathrm{N}=230)$} \\
\hline & & $\begin{array}{l}\text { Factor } \\
\text { loading }\end{array}$ & AVE & C.R. & $\alpha$ & $\begin{array}{l}\text { Factor } \\
\text { loading }\end{array}$ & AVE & C.R. & $\alpha$ \\
\hline \multirow{4}{*}{ Flow experience } & FE1 & 0.79 & \multirow{4}{*}{0.71} & \multirow{4}{*}{0.91} & \multirow{4}{*}{0.86} & 0.78 & \multirow{4}{*}{0.66} & \multirow{4}{*}{0.89} & \multirow{4}{*}{0.83} \\
\hline & FE2 & 0.85 & & & & 0.84 & & & \\
\hline & FE3 & 0.86 & & & & 0.80 & & & \\
\hline & FE4 & 0.86 & & & & 0.85 & & & \\
\hline \multirow{3}{*}{ Perceived control } & PC1 & 0.82 & \multirow{3}{*}{0.68} & \multirow{3}{*}{0.86} & \multirow{3}{*}{0.76} & 0.62 & \multirow{3}{*}{0.57} & \multirow{3}{*}{0.79} & \multirow{3}{*}{0.61} \\
\hline & PC2 & 0.81 & & & & 0.78 & & & \\
\hline & PC3 & 0.84 & & & & 0.84 & & & \\
\hline
\end{tabular}




\begin{tabular}{|c|c|c|c|c|c|c|c|c|c|}
\hline Tabl & & & & & & & & & \\
\hline \multirow{3}{*}{ Perceived ease of use } & PEU1 & 0.69 & \multirow{3}{*}{0.59} & \multirow{3}{*}{0.81} & \multirow{3}{*}{0.67} & 0.75 & \multirow{3}{*}{0.59} & \multirow{3}{*}{0.81} & \multirow{3}{*}{0.65} \\
\hline & PEU2 & 0.76 & & & & 0.77 & & & \\
\hline & PEU3 & 0.85 & & & & 0.78 & & & \\
\hline \multirow{3}{*}{ Online social Interaction } & ON1 & 0.84 & \multirow{3}{*}{0.67} & \multirow{3}{*}{0.86} & \multirow{3}{*}{0.76} & 0.83 & \multirow{3}{*}{0.62} & \multirow{3}{*}{0.83} & \multirow{3}{*}{0.69} \\
\hline & ON2 & 0.86 & & & & 0.74 & & & \\
\hline & ON3 & 0.77 & & & & 0.78 & & & \\
\hline \multirow{3}{*}{ Offline social Interaction } & OFF1 & 0.86 & \multirow{3}{*}{0.69} & \multirow{3}{*}{0.87} & \multirow{3}{*}{0.78} & 0.75 & \multirow{3}{*}{0.57} & \multirow{3}{*}{0.80} & \multirow{3}{*}{0.62} \\
\hline & OFF2 & 0.83 & & & & 0.79 & & & \\
\hline & OFF3 & 0.81 & & & & 0.73 & & & \\
\hline \multirow{4}{*}{ Customer engagement } & CE1 & 0.84 & \multirow{4}{*}{0.57} & \multirow{4}{*}{0.84} & \multirow{4}{*}{0.75} & 0.79 & \multirow{4}{*}{0.59} & \multirow{4}{*}{0.85} & \multirow{4}{*}{0.77} \\
\hline & CE2 & 0.81 & & & & 0.84 & & & \\
\hline & CE3 & 0.68 & & & & 0.75 & & & \\
\hline & CE4 & 0.68 & & & & 0.79 & & & \\
\hline \multirow{2}{*}{$\begin{array}{l}\text { Continuous playing } \\
\text { games intention }\end{array}$} & $\mathrm{Cl} 1$ & 0.85 & \multirow{2}{*}{0.76} & \multirow{2}{*}{0.86} & \multirow{2}{*}{0.68} & 0.86 & \multirow{2}{*}{0.75} & \multirow{2}{*}{0.86} & \multirow{2}{*}{0.67} \\
\hline & $\mathrm{Cl} 2$ & 0.89 & & & & 0.89 & & & \\
\hline
\end{tabular}

Table 5: Discriminant validity analysis for sub-samples: LOL $(\mathrm{N}=301)$

\begin{tabular}{|l|l|l|l|l|l|l|l|}
\hline Constructs & FE & PC & PEU & ON & OFF & CE & CI \\
\hline FE & 0.84 & & & & & & \\
\hline PC & 0.35 & 0.82 & & & & & \\
\hline PEU & 0.36 & 0.54 & 0.77 & & & & \\
\hline ON & 0.28 & 0.59 & 0.55 & 0.82 & & & \\
\hline OFF & 0.52 & 0.51 & 0.44 & 0.38 & 0.83 & & \\
\hline CE & 0.63 & 0.53 & 0.50 & 0.47 & 0.55 & 0.75 & \\
\hline Cl & 0.35 & 0.50 & 0.55 & 0.43 & 0.45 & 0.45 & 0.87 \\
\hline
\end{tabular}

Table 6: Discriminant validity analysis for sub-samples: Arena of Valor $(\mathrm{N}=230)$

\begin{tabular}{|l|l|l|l|l|l|l|l|}
\hline Constructs & FE & PC & PEU & ON & OFF & CE & Cl \\
\hline FE & 0.81 & & & & & & \\
\hline PC & 0.60 & 0.75 & & & & & \\
\hline PEU & 0.43 & 0.63 & 0.77 & & & & \\
\hline ON & 0.35 & 0.30 & 0.29 & 0.79 & & & \\
\hline OFF & 0.48 & 0.62 & 0.57 & 0.39 & 0.75 & & \\
\hline CE & 0.57 & 0.63 & 0.62 & 0.45 & 0.67 & 0.77 & \\
\hline Cl & 0.45 & 0.59 & 0.47 & 0.23 & 0.52 & 0.55 & 0.87 \\
\hline
\end{tabular}

\subsection{Structural Model Analysis}

We test hypotheses $\mathrm{H} 1$ to $\mathrm{H} 4 \mathrm{~b}$ by examining the path coefficients between variables for the full sample. As shown in Figure $2, \mathrm{R}^{2}$ results show that $63 \%$ of the variance of customer engagement can be explained by flow experience, perceived control, perceived ease of use, online social interaction, and offline social interaction. In addition, customer engagement explains $32 \%$ of the variance in continuous playing MOBA games intention. Customer engagement is found to be significantly associated with continuous playing games intention $(\beta=0.56, t=19.27)$, which supports hypothesis $H 1$. Customer engagement is positively related to flow experience $(\beta=0.33, t=8.27)$, perceived control $(\beta=0.13, t=3.35)$, perceived ease of use $(\beta=0.15, t=3.62)$, online social interaction $(\beta=0.12, t=2.92)$, and offline social interaction $(\beta=0.29, \mathrm{t}=6.66)$, supporting hypotheses $\mathrm{H} 2, \mathrm{H} 3 \mathrm{a}, \mathrm{H} 3 \mathrm{~b}, \mathrm{H} 4 \mathrm{a}$, and $\mathrm{H} 4 \mathrm{~b}$.

In addition, we study the structural model with data from two sub-samples separately to test the generalizability of our framework for empirical comparison. The results for the LOL and Arena of Valor samples are demonstrated in figures 3 and 4, respectively. They show that all the path coefficients are significant for both sub-samples; that is, hypotheses $\mathrm{H} 1$ to $\mathrm{H} 4 \mathrm{~b}$ are supported by the full sample and both sub-samples analyses. 


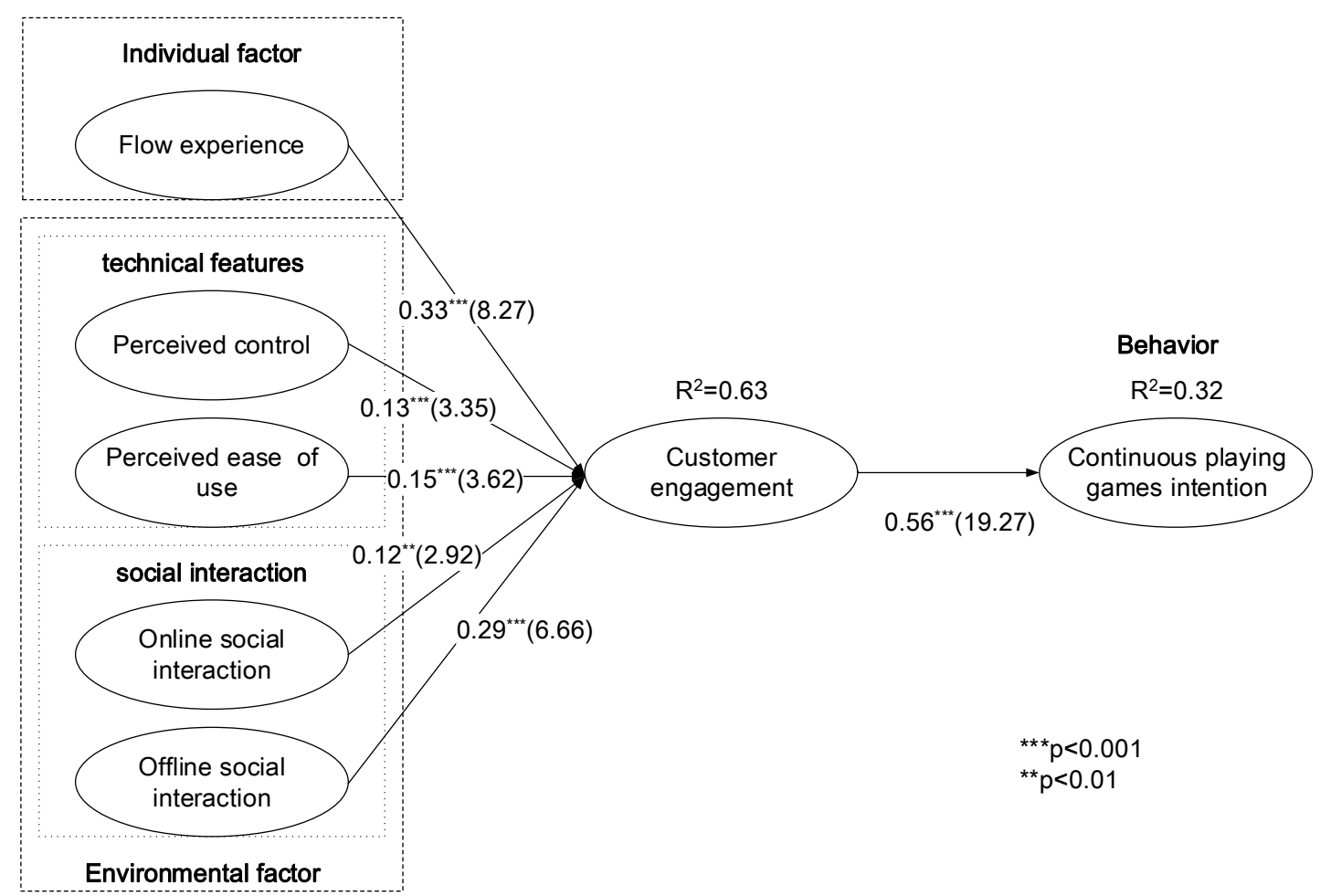

Figure 2: Structural model analysis result for the full sample $(\mathrm{N}=531)$

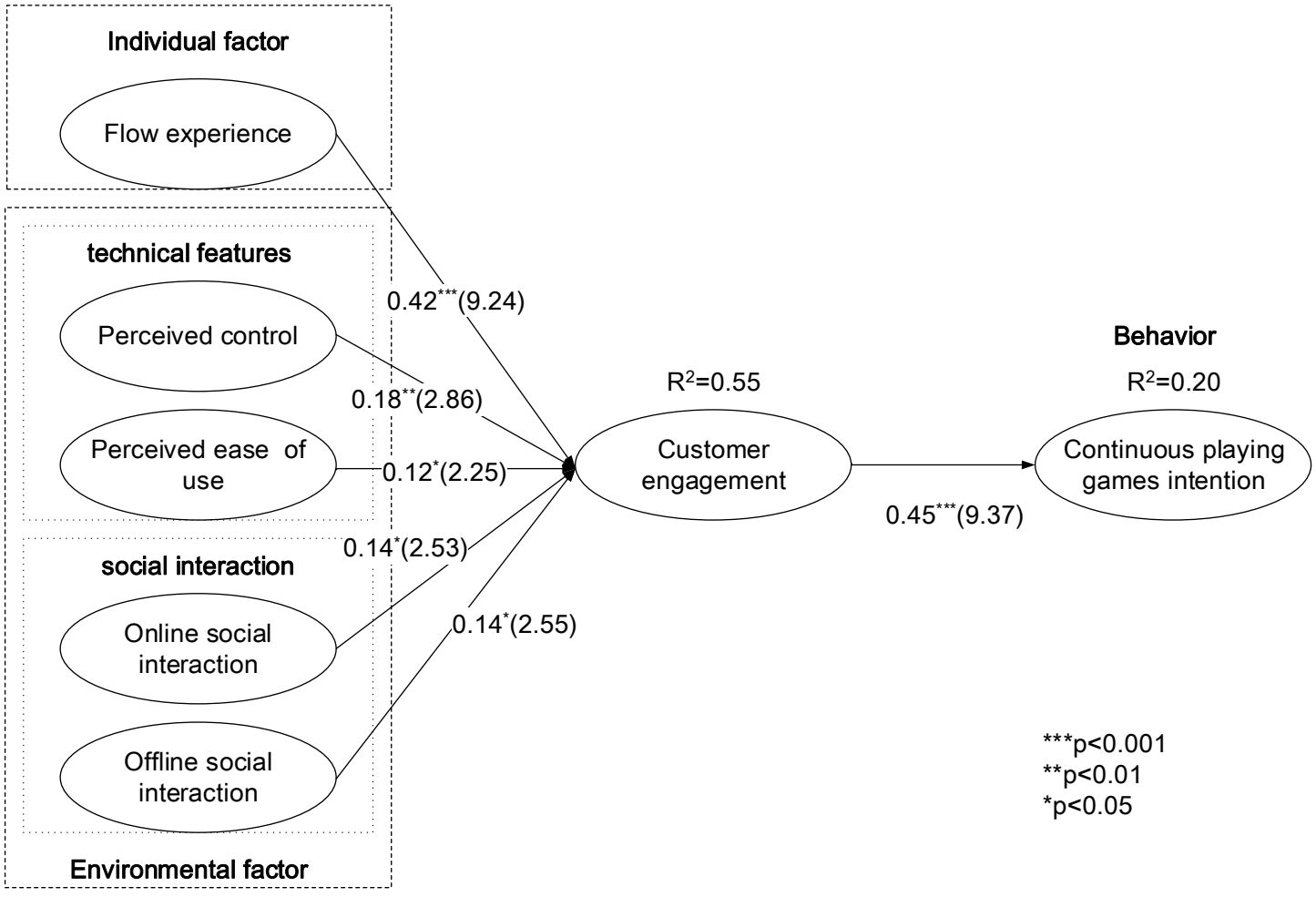

Figure 3: Structural model analysis result for LOL $(\mathrm{N}=301)$ 


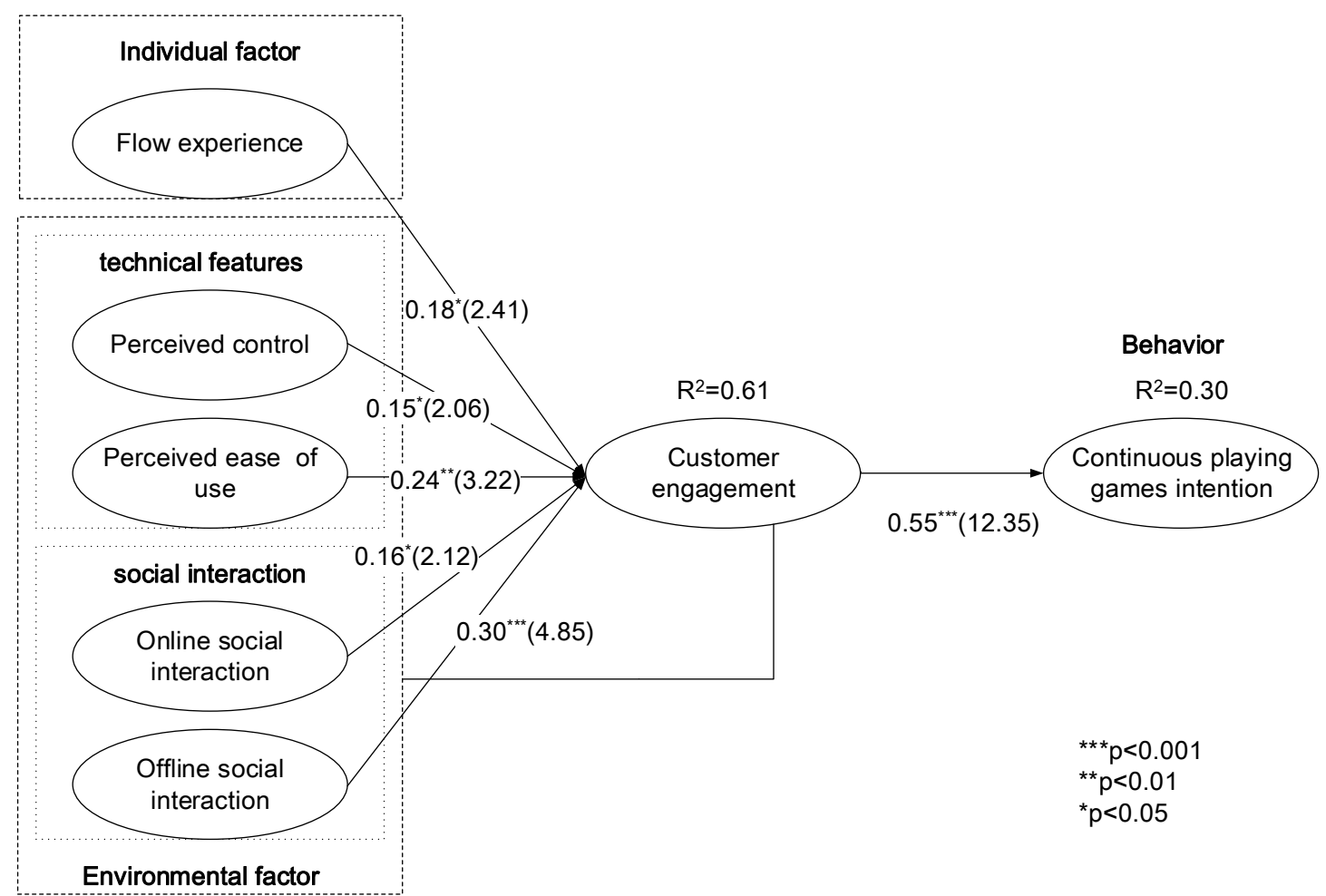

Figure 4: Structural model analysis result for Arena of Valor $(N=230)$

\subsection{Group Comparison Analysis}

To test the differences in playing MOBA games on different mobile devices, we adopt the process of subgroup comparison proposed by Keil et al. [44]. The subgroup analysis results for LOL and Arena of Valor samples are shown in Table 7. We use the $T_{\text {spooled }}$ value to evaluate the difference of each path, as follows:

$$
t_{\text {spooled }}=\frac{\text { Path }_{\text {sample } 1}-P a t h_{\text {sample } 2}}{\sqrt{S . E_{\text {sample } 1}^{2}+S \cdot E_{\text {sample } 2}^{2}}},
$$

Path in the model is each Path Coefficient, and S.E. is the Standard Deviation of each path.

Therefore, the path from flow experience to customer engagement was significantly stronger among LOL players. However, the paths from perceived ease of use and offline social interaction to customer engagement were significantly stronger among Arena of Valor players. Finally, there was no significant difference in the three paths between LOL players and Arena of Valor players (from Perceived control to customer engagement, from online social interaction to customer engagement and from customer engagement to continuous playing games intention).

Table 7: Sub-group analysis between LOL $(\mathrm{N}=301)$ and Arena of Valor $(\mathrm{N}=230)$

\begin{tabular}{|l|l|l|l|}
\hline \multirow{2}{*}{ Path } & \multicolumn{2}{|l|}{ Path Coefficient/ Standard Deviation } & \multirow{2}{*}{$T_{\text {spooled }}$} \\
\cline { 2 - 3 } & LOL & Arena of Valor & \\
\hline $\begin{array}{l}\text { Flow experience } \rightarrow \\
\text { Customer engagement }\end{array}$ & $0.417 / 0.0459$ & $0.175 / 0.0748$ & $2.89^{\star *}$ \\
\hline $\begin{array}{l}\text { Perceived control } \rightarrow \\
\text { Customer engagement }\end{array}$ & $0.175 / 0.0595$ & $0.147 / 0.0706$ & $0.30 \mathrm{~ns}$ \\
\hline $\begin{array}{l}\text { Perceived ease of use } \rightarrow \\
\text { Customer engagement }\end{array}$ & $0.120 / 0.041$ & $0.240 / 0.0429$ & $-2.00^{\star}$ \\
\hline $\begin{array}{l}\text { Online social interaction } \rightarrow \\
\text { Customer engagement }\end{array}$ & $0.135 / 0.0537$ & $0.158 / 0.0718$ & $-0.26 \mathrm{~ns}$ \\
\hline
\end{tabular}




\begin{tabular}{|l|l|l|l|}
\hline \multicolumn{3}{|l|}{ Table 7: continuation } \\
\hline $\begin{array}{l}\text { Offline social interaction } \rightarrow \\
\text { Customer engagement }\end{array}$ & $0.135 / 0.0540$ & $0.300 / 0.0637$ & $-1.99^{*}$ \\
\hline $\begin{array}{l}\text { Customer engagement } \rightarrow \\
\text { continuous playing games intention }\end{array}$ & $0.448 / 0.0478$ & $0.549 / 0.0441$ & $-1.51 \mathrm{~ns}$ \\
\hline
\end{tabular}

\subsection{Result Discussion}

The empirical study supports most of our hypotheses. First, customer engagement in the examined MOBA games positively relates to continuous playing games intention. This result verifies that customer engagement further elevates customers' positive intention [24], which is consistent with previous research. Thus, if people highly engage in MOBA games psychologically and behaviorally, they are more likely to keep playing this game in the future, subsequently, remaining freshness of the game for a long time, and not easily to play alternative games. While there was no significant difference in the path from customer engagement to continuous playing games intention between LOL players and Arena of Valor players. In future, customers may be more inclined to use their mobile phones to play games because of the convenience.

Second, we verify the relationship between individual factors and customer engagement. We discover that flow experience is significantly associated with customer engagement, which is an important antecedent. In other words, strengthening game experience is the key factor to induce players' positive engagement. Comprehensibility, immersion in games and enjoyable experience tend to increase players' frequency and time of playing games, then, help to build a long-term engagement relationship with games. Although this has been confirmed by previous research [37], but we conduct a group comparison analysis to compare the influence of flow experience on customer engagement between PCs and mobile phones, and surprised to find that the influence of flow experience on customer engagement on PCs is greater than on mobile phones. This is because when playing MOBA games on PC, the game screen is very fluid and rich in content; hence, users have a more enhanced experience than on mobile phones. Therefore, for firms, advancing game experience of PC users can attract and retain potential customers, making it easier for players to establish engagement relationship with the game.

Third, the technical features, including perceived control and perceived ease of use, are positively associated with customer engagement. The effect of perceived ease of use on customer engagement is slightly higher on PC than on a mobile phone, while there is no significant difference between PC and mobile phone in terms of perceived control, which differs from previous studies [28]. It is easy to understand that even on PC and mobile phone, players' perceived control and perceived ease of use of the game will have a positive effect on customer engagement, but mobile games are easier to operate, which can be played anytime and anywhere, so as to build positive customer engagement. In addition, the sense of immersion and control will improve the game experience to attract customers to spend more time and energy on this game, and to maintain continuous loyalty in the future.

Fourth, online and offline social interaction remain significantly associated with customer engagement. Especially, the effect of offline social interaction on customer engagement on mobile phones is significantly higher than that on PC. This is the latest discovery, which is different from predecessors, who just investigated the influence of interaction, but fail to distinguish online interaction and offline interaction [55], [60]. In fact, due to the convenience and maneuverability of mobile phones, players can form a team to play together offline, which is convenient for chatting and cooperation, that is the catalyst for game experience and engagement. However, the online communication with PC is limited by environmental factors (such as time, place, network). Accordingly, customer engagement can be better promoted by the offline interaction of mobile games.

Overall, our findings support that playing MOBA games on different mobile devices has different influences through these variables. This verifies the premise of Triadic reciprocal determinism, which emphasizes the influence of both individual and environmental factors on behavior. Flow experience, technical features, and social interaction are the core factors that influence customer engagement, especially flow experience. The formation of customer engagement can promote a player's intention to continuously play games.

\section{Implication}

In this section, we describe the theoretical contributions and practical implications as follow.

\subsection{Theoretical Implications}

First, customer engagement has been proved to enhance relationship between customers in the field of marketing, but few people have studied the role of customer engagement on participation and loyalty in MOBA games. In fact, online games provide a highly engaged situation, which is a key driver to promote customer behavior [31]. In this research, we tested the relationship between customer engagement and continuous playing. Although customer 
engagement in customer loyalty or satisfaction has been studied and received empirical support [6], its mechanism still requires further exploration. Therefore, we studied the effects of flow experience, perceived control, perceived ease of use, online and offline social interaction on customer engagement and continuous playing games intention. The findings show that customers can switch from ordinary players to active engaged players, then having a sense of novelty about the games constantly through the stimulation of individual and environmental factors. Accordingly, it enhances our understanding of the relationship between customers' experience and consumer behavior in ecommerce gaming contexts.

Second, we introduce Triadic reciprocal determinism into the MOBA field and explain the drivers of customer engagement from a new perspective. We examined the effects of personal factors (flow experience) and environmental factors (perceived control, perceived ease of use, offline and online interaction) on customer engagement and individual behavior (continuous playing games intentions). The result shows that personal and environmental factors together explained $63 \%$ of the variance in customer engagement, and thus further contribute to the existing knowledge of customer engagement. Unlike previous studies such as Hamari and Keronen [27], Kim and Kim [46], Huang et al. [40], Liao and Teng [53] show that only individual factors (experience, personality traits, etc.) or environmental elements (relationship bond, perceived ease of use, perceived usefulness, etc.) influence continuous playing intentions. As such, this study will stimulate more research on the mechanisms involved in the formation and development of customer engagement.

Third, on different terminals, we identified the key drivers influencing customer engagement by comparing the personal experience, the characteristics of game technology, the relationship between customer engagement and behavior among PC and mobile gamers. In the PC model (LOL), flow experience exerted the highest effect on customer engagement, whereas perceived control had a secondary influence on it. Thus, when playing MOBA games on PC, players experience perfect picture quality, vivid characters, fluid screen and higher resolution in content; hence, users may have an enhanced experience. Computer games require players to have a higher threshold of control. Some players like playing MOBA games on PC, demonstrating their ability to operate the device. While in the mobile phone model (Arena of Valor), offline social interaction exerted the highest effect on customer engagement, whereas perceived ease of use had a secondary influence on it. Thus, when playing mobile games, users do not need to text or send voice messages to their teammates. They usually sit together to play King of Glory and talk to each other directly offline, maintaining a good social relationship with each other. Furthermore, mobile games are easy to play, making full use of an individual's free time. In addition, it is possible for users to play mobile games on their way home from work or while waiting for a bus.

\subsection{Practical Implications}

This study also has some implications for game developers who work to improve their games and develop better products.

First, based on our findings, game developers should be aware of the importance of customer engagement, and thus, cultivate it to enhance consumers' desire to continue playing games in the future. As for our research, customer engagement explained $32 \%$ of the variance in continuous playing games intention, indicating that some other important influencing factors have not been included in the model. Even so, our research shows that customer engagement is a pre-influencing factor of continuous playing games intention. Therefore, enterprises should track the formation of customer engagement and foster a highly coincident situation. Especially, companies can retain loyal customers and build long-lasting relationships by tracking highly-coincident consumers and fostering them.

Second, game developers should focus on how to improve customer engagement. For mobile games, offline interaction plays a key role in facilitating customer engagement. Thus, game developers can use offline social interaction to promote and popularize gaming products. For example, friends share games through social media or gaming platforms, which are also the main sources of advertising games. Besides, a series of activities and events, such as the sun glamour list, the hand-painted activities of the same person, the dream sound, the Player Killing (PK) race of the University and the PK competition for the whole community, provide better opportunities for players to experience social games. A game community can be established to increase communication between players and meet their social needs. Mobile games especially emphasize the ease of operation. With the help of the virtual game community, game developers can provide assistance to mobile gamers for improving their skills by investigating the operating habits of users, which can make it easier to get started. For PC games, we found that players pay more attention to flow experience in PC gaming. Therefore, to meet customer demands, game developers should focus on enhancing the PC gaming experience. Marketers should pay more attention to design flow experience, add rank match and activity coupons to attract customers' in-depth game flow experience. Furthermore, the balance between easy playing ability and control difficulty is very important for customer engagement. While emphasizing the ease of operation, game developers can explore users' control experience, design games with different difficulty coefficients, add levels, and choose new characters to make games fresher and more challenging. 


\section{Limitations and Future Research}

Several limitations of this study can be addressed in future research. First, we conducted our investigation in mainland China. Data were collected from two popular MOBA games. Future studies could extend our methodology to other popular MOBA games or other types of video games. Besides, based on the Triadic reciprocal determinism, other variables of individual and environmental factors may influence individual behavior, such as achievement experience, role-playing, and perceived usefulness. Future studies could explore the influence of these variables on continuous playing.

In addition, we compared two mobile terminals, PCs and mobile phones. However, other devices also allow MOBA games, such as tablet PCs and Pad devices. Consequently, the flow experience on these devices may also be different. Thereby, future studies should consider these devices for a detailed empirical comparison to explore their respective influences. From our research findings, we see that the influence of interaction perception on engagement between PCs and mobile phones is quite different; therefore, it is possible to discuss the interactive effect of online and offline interaction on the experience perception of players in the future. For example, Zhong tested whether collective MMORPG (Massively Multiplayer Online Role-Playing Games) play influences offline social capital via the mediation of online social capital [71].

Furthermore, MOBA games require gamers to form teams to compete. Therefore, MOBA games are the perfect context for future studies to examine competition issues around virtual teams. Yang, Tong, and Teo [73] can be one example, although they used MMORPG. I suppose MOBA games are a better context for addressing virtual team issues.

\section{Acknowledgments}

This paper is supported by the National Social Foundation of China (No: 14BGL055).

Dr. Guo Lingyun is the corresponding author of this paper.

\section{Websites List}

Site1: Netease news (in Chinese), 2016 Sep 15.

http://news.163.com/16/0915/23/C11RD0QD000181N4.html.

Site2: Mobile game global market data (in Chinese), 2017 Apr 14.

http://www.yxdown.com/news/201704/348090.html.

Site3: Observer news (in Chinese), 2017 June 16.

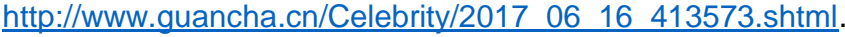

Site 4: Sojump

www.Sojump.com

\section{References}

[1] T. Anning-Dorson, Customer invovement capability and service firm performance: The mediating role of innovation, Journal of Business Research, vol. 86, pp. 269-280, 2018.

[2] A. Bandura, The self system in reciprocal determinism, American Psychologist, vol. 33, pp. 344-358, 1978.

[3] A. Bandura, The explanatory and predictive scope of self-efficacy theory, Journal of Social and Clinical Psychology, vol. 4, no. 3, pp. 359-373, 1986.

[4] A. Bandura, Social cognitive theory: An agentic perspective, Asian Journal of Social Psychology, vol. 2, no. 1, pp. 21-41, 1999.

[5] C. Barlett, C. D. Rodeheffer, R. Baldassaro, M. Hinkin, and R. Harris, The effect of advances in video game technology and content on aggressive cognitions, hostility, and heart rate, Media Psychology, vol. 11, no. 4, pp. 540-565, 2008.

[6] S. Bitter and S. Grabner-Kräuter, Consequences of customer engagement behavior: When negative facebook posts have positive effects, Electronic Marketing, vol. 26, no. 3, pp. 219-231, 2016.

[7] R. Brodie, L. Hollebeek, B. Juric, and A. Ilic, Customer engagement: conceptual domain, fundamental propositions, and implications for research, Journal of Service Research, vol. 14, no. 3, pp. 252-271, 2011.

[8] L. Bowden, The process of customer engagement: a conceptual framework, Journal of Marketing Theory and Practice, vol. 17, no. 1, pp. 63-74, 2009.

[9] A. Busali, A. Hussin and N. lahad, Factors influencing customer engagement in social commerce websites: A systematic literature review, Journal of Theoretical and Applied Electronic Commerce Research, vol. 14, no. 2, pp. 1-14, 2019. 
[10] E. Calvillo-Gámez, P. Cairns and A. L. Cox, Assessing the Core Elements of the Gaming Experience. Game User Experience Evaluation. Cham: Springer, pp.37-62.

[11] C. Chang, Examining users' intention to continue using social network games: A flow experience perspective, Telematics \& Informatics, vol. 30, no. 4, pp. 311-321, 2013.

[12] Y. Chang and D. Zhu, The role of perceived social capital and flow experience in building users' continuance intention to social networking sites in China, Computers in Human Behavior, vol. 28, no. 3, pp. 995-1001, 2012.

[13] J. Chan, H. Weng and C. Huang, A multilevel analysisi of customer engagement, its antecedents, and the effects on service innovation, Total Quality Management \& Business Excellence, vol. 29, no. 3-4, pp. 410-428, 2018.

[14] C. Cheung, X. Shen, Z. Lee, and T. Chan, Promoting sales of online games through customer engagement, Electronic Commerce Research and Applications, vol. 14, no. 4, pp. 241-250, 2015.

[15] D. Choi and J. Kim, Why people continue to play online games: In search of critical design factors to increase customer loyalty to online contents, CyberPsychology \& Behavior, vol. 7, no. 1, pp. 11-24, 2004.

[16] W. Chin, The partial least squares approach to structural equation modeling, Modern Methods for Business Research, vol. 295, no. 2, pp. 295-336, 1998.

[17] J. Chung, Social interaction in online support groups: preference for online social interaction over offline social interaction, Computers in Human Behavior, vol. 29, no. 4, pp. 1408-1414, 2013.

[18] T. Chou and C. Ting, The role of flow experience in cyber-game addiction, Cyberpsychology \& Behavior, vol. 6 , no. 6 , pp. 663-675, 2003

[19] T. Connolly, E. Boyle, E. Macarthur, T. Hainey, and J. Boyle, A systematic literature review of empirical evidence on computer games and serious games, Computers \& Education, vol. 59, no. 2, pp. 661-686, 2012.

[20] M. Csikszentmihalyi and I. Csikszentmihalyi, Beyond Boredom and Anxiety. San Francisco: Jossey-Bass, 1975.

[21] F. Davis, Perceived usefulness, perceived ease of use, and user acceptance of information technology, Mis Quarterly, vol. 13, no. 3, pp. 319-340, 1989.

[22] C. Fornell and D. Larcker, Evaluating structural equation models with unobservable variables and measurement error, Journal of Marketing Research, vol. 18, no. 1, pp. 39-50, 1981.

[23] C. Green and D. Bavelier, Action video game modifies visual selective attention, Nature, vol. 423, no. 6939, pp. 534-537, 2003.

[24] L. Guo, M. Zhang, K. Kang, and M. Hu, Transforming followers into fans: A study of Chinese users of the eechat official account, Online Information Review, vol. 41, no.7, pp. 1029-1045.

[25] L. Guo, M. Zhang and Y. Wang, Effects of customers' psychological characteristics on their engagement behavior in company social networks, Social Behavior \& Personality, vol. 44, no. 10, pp. 1661-1670, 2016.

[26] M. Griffiths and N. Hunt, Dependence on computer games by adolescents, Psychological Reports, vol. 82, no. 2, pp. 475-480, 1998.

[27] J. Hamari and L. Keronen, Why do people play games? A meta-analysis, International Journal of Information Management, vol. 37, no. 3, pp. 125-141, 2017.

[28] J. M. Hansen, G. Saridakis and V. Benson, Risk, trust, and the interaction of perceived ease of use and behavioral control in predicting consumers' use of social media for transactions, Computers in Human Behavior, vol. 80, pp. 197-206, 2018.

[29] T. Hartmann and C. Klimmt, Gender and computer games: Exploring females' dislikes, Journal of ComputerMediated Communication, vol. 11, no. 4, pp. 910-931, 2006

[30] L. Harmat, Ö. de Manzano, T. Theorell, L. Högman, H. Fischer, and F. Ullén, Physiological correlates of the flow experience during computer game playing, International Journal of Psychophysiology, vol. 97, no. 1, pp. 1-7, 2015.

[31] T. Harwood and T. Garry, An investigation into gamification as a customer engagement experience environment, Journal of Services Marketing, vol. 29, no. 6/7, pp. 533-546, 2015.

[32] S. Hasan, Multiplayer gaming for low-end mobile phones: Gaming between basic mobile phones, handheld devices and computer platforms, in Proceedings Games Innovations Conference (ICE-GIC), 2010 International IEEE Consumer Electronics Society's, Hong Kong, 2010, pp. 1-5.

[33] C. Herrando, J. Jimenez-Martinez and M. J. Martin De Hoyos, From sPassion to sWOM: The role of flow, Online Information Review, vol. 42, no. 2, pp.191-204, 2018.

[34] D. Hoffman and T. Novak, Marketing in hypermedia computer-mediated environments: Conceptual foundations, Journal of Marketing, vol. 60, no. 3, pp. 50-68, 1996.

[35] C. Hsu and J. Lin, Examining Social Networking O2O Apps User Loyalty, Journal of Computer Information Systems, pp. 1-9, 2018.

[36] C. Hsu and $\mathrm{H}$. Lu, Why do people play on-line games? An extended TAM with social influences and flow experience, Information \& Management, vol. 41, no. 7, pp. 853-868, 2004.

[37] M. Hu, M. Zhang, and N. Luo, Understanding participation on video sharing communities, Computers in Human Behavior, vol. 62, pp. 105-115, 2016.

[38] M. Hu, M. Zhang and Y. Wang, Why do audiences choose to keep watching on live video streaming platforms? An explanation of dual identification framework, Computers in Human Behavior, vol. 75, pp. 594-606, 2017.

[39] H. Huang, T. Cheng, W. Huang, and C. Teng, Impact of online gamers' personality traits on interdependence, network convergence, and continuance intention: Perspective of social exchange theory, International Journal of Information Management, vol. 38, no. 1, pp. 232-242, 2018.

[40] T. Huang, Z. Bao and Y. Li, Why do players purchase in mobile social network games? An examination of customer engagement and of uses and gratifications theory, Program, vol. 51, no. 3, pp. 259-277, 2017.

[41] Y. Inal and K. Cagiltay, Flow experiences of children in an interactive social game environment, British Journal of Educational Technology, vol. 38, no. 3, pp. 455-464, 2010. 
[42] H. Jeon, H. Ahn and G. Yu, What makes people react to the posts on the brand pages of mobile social network games?, Online Information Review, vol. 40, no. 3, pp. 435-448, 2016.

[43] D. Jin, F. Chee and S. Kim, Transformative mobile game culture: A sociocultural analysis of Korean mobile gaming in the era of smartphones, International Journal of Cultural Studies, vol. 18, no. 4, pp. 413-429, 2015.

[44] M. Keil, B. Tan, K. Wei, T. Saarinen, and A. Wassenaar, A cross-cultural study on escalation of commitment behavior in software projects, MIS Quarterly, vol. 24, no. 2, pp. 299-325, 2000.

[45] J. Kim, C. Lee and T. Elias, Factors affecting information sharing in social networking sites amongst university students, Online Information Review, vol. 39, no. 3, pp. 290-309, 2015.

[46] M. Kim and J. Kim, The effects of perceived online justice on relational bonds and engagement intention: Evidence from an online game community, Computers in Human Behavior, vol. 84, pp. 410-419, 2018.

[47] D. King, P. Delfabbro and M. Griffiths, Video game structural characteristics: A new psychological taxonomy, International Journal of Mental Health and Addiction, vol. 8, no. 1, pp. 90-106, 2010.

[48] T. Klaus and C. Changchit, Toward an understanding of consumer attitudes on online review usage, Journal of Computer Information Systems, vol. 59, no. 3, pp. 277-286, 2019.

[49] M. Koufaris, Applying the technology acceptance model and flow theory to online consumer behavior, Information Systems Research, vol. 13, no. 2, pp. 205-223, 2002.

[50] H. P. Lu and M. R. Lee, Demographic differences and the antecedents of blog stickiness, Online Information Review, vol. 34, no. 1, pp. 21-38, 2010.

[51] M. Lee and T. Tsai, What drives people to continue to play online games? An extension of technology model and theory of planned behavior, International Journal of Human-Computer Interaction, vol. 26, no. 6, pp. 601-620, 2010.

[52] S. Lee, S. Lee and S. Chan-Olmsted, An empirical analysis of tablet PC diffusion, Telematics and Informatics, vol. 34, no. 2, pp. 518-527, 2017.

[53] G. Liao and C. Teng, You can make it: expectancy for growth increases online gamer loyalty, International Journal of Electronic Commerce, vol. 21, no. 3, pp. 398-423, 2017.

[54] Y. Lu, T. Zhou and B. Wang, Exploring Chinese users' acceptance of instant messaging using the theory of planned behavior, the technology acceptance model, and the flow theory, Computers in Human Behavior, vol. 25, no. 1, pp. 29-39, 2009.

[55] S. Mamonov, M. Koufaris and R. Benbunan-Fich, The role of the sense of community in the sustainability of social network sites, International Journal of Electronic Commerce, vol. 20, no. 4, pp. 470-498, 2016.

[56] M. Moliner, D. Monferrer and M. Estrada, Consequences of customer engagement and customer self-brand connection, Journal of Services Marketing, vol. 32, no. 4, pp. 387-399, 2018.

[57] S. Molinillo, F. Liébana-Cabanillas and R. Anaya-Sánchez, A social commerce intention model for traditional ecommerce sites, Journal of Theoretical and Applied Electronic Commerce Research, vol. 13, no. 2, pp. 80-93, 2018.

[58] E. Park, S. Baek, J. Ohm, and H. Chang, Determinants of player acceptance of mobile social network games: an application of extended technology acceptance model, Telematics \& Informatics, vol. 31, no. 1, pp. 3-15, 2014.

[59] H. Park and S. Kim, A Bayesian network approach to examining key success factors of mobile games, Journal of Business Research, vol. 66, no. 9, pp. 1353-1359, 2013.

[60] K. Payne, M. J. Keith, R. M. Schuetzler, and J. S. Giboney, Examining the learning effects of live streaming video game instruction over Twitch, Computers in Human Behavior, vol. 77, pp. 95-109, 2017.

[61] Y. Qu, W. Rong, H. Chen, Y. Ouyang, and Z. Xiong, Influencing factors analysis for a social network web based payment service in China, Journal of Theoretical and Applied Electronic Commerce Research, vol. 13, no. 3, pp. 99-113, 2018.

[62] G. Saposnik, W. Mcilroy, R. Teasell, K. Thorpe, M. Bayley, D. Cheung, K. Thorpe, L. Cohen, and M.Bayley, Effectiveness of virtual reality using wii gaming technology in stroke rehabilitation: A pilot randomized clinical trial and proof of principle, Stroke, vol. 32, no. 1, pp. 312-321, 2010.

[63] Y. Seo, M. Buchanan-Oliver and K. Fam, Advancing research on computer game consumption: A future research agenda, Journal of Consumer Behaviour, vol. 14, no. 6, pp. 353-356, 2015.

[64] M. Shafiee and N. Bazargan, Behavioral customer loyalty in online shopping: The role of E-service quality and erecovery, Journal of Theoretical and Applied Electronic Commerce Research, vol. 13, no. 1, pp. 26-38, 2018.

[65] A. Suh, C. Cheung, M. Ahuja, and C. Wagner, Gamification in the workplace: The central role of the aesthetic experience, Journal of Management Information Systems, vol. 34, no. 1, pp. 268-305, 2017.

[66] P. Sweetser and P. Wyeth, GameFlow: a model for evaluating player enjoyment in games, Computers in Entertainment, vol. 3, no. 3, pp. 3-3, 2005.

[67] S. Trepte, L. Reinecke and K. Juechems, The social side of gaming: How playing online computer games creates online and offline social support, Computers in Human Behavior, vol. 28, no. 3, pp. 832-839, 2012.

[68] A. Tyack, P. Wyeth and D. Johnson, The appeal of moba games: What makes people start, stay, and stop, in Proceedings of the 2016 Annual Symposium on Computer-Human Interaction in Play, ACM, Austin, Texas, USA, 2016, pp. 313-325.

[69] G. Van Noort, H. Voorveld and E. Van Reijmersdal, Interactivity in brand web sites: Cognitive, affective, and behavioral responses explained by consumers' online flow experience, Journal of Interactive Marketing, vol. 26, no. 4, pp. 223-234, 2012

[70] V. Venkatesh, M. Morris, G. Davis, and F. Davis, User acceptance of information technology: Toward a unified view, MIS Quarterly, vol. 27, no. 3, pp. 425-478, 2003.

[71] E. Wang, Perceived control and gender difference on the relationship between trialability and intent to play new online games, Computers in Human Behavior, vol. 30, pp. 315-320, 2014. 
[72] B. Wu and X. Chen, Continuance intention to use MOOCs: Integrating the technology acceptance model (TAM) and task technology fit (TTF) model, Computers in Human Behavior, vol. 67, pp. 221-232, 2017.

[73] X. Yang, Y. Tong and H. Teo, Fostering fast-response spontaneous virtual team: Effects of member skill awareness and shared governance on team cohesion and outcomes, Journal of the Association Information Systems, vol. 16, no. 11, pp. 919-946, 2015.

[74] N. Yee, The psychology of massively multi-user online role-playing games: Motivations, emotional investment, relationships and problematic usage, in Avatars at Work and Play (R. Schroeder and A. S. Axelsson, Eds.). Dordrecht: Springer, 2006, pp. 187-207.

[75] V. Zeithaml, A. Parasuraman and A. Malhotra, Service quality delivery through web sites: A critical review of extant knowledge, Journal of Academy Marketing Science, vol. 30, no. 4, pp.362, 2002.

[76] M. Zhang, L. Guo, M. Hu, and W. Liu, Influence of customer engagement with company social networks on stickiness: Mediating effect of customer value creation, International Journal of Information Management, vol. 37, no. 3, pp. 229-240, 2017

[77] Q. Zhao, C. Chen and J. Wang, The effects of psychological ownership and TAM on social media loyalty: An integrated model, Telematics \& Informatics, vol. 33, no. 4, pp. 959-972, 2016.

[78] Z. Zhong, The effects of collective MMORPG (Massively Multiplayer Online Role-Playing Games) play on gamers' online and offline social capital, Computers in Human Behavior, vol. 27, no. 6, pp. 2352-2363, 2011. 


\title{
Appendix A: Questionnaire Items
}

\author{
Flow experience \\ FE1: Playing $\mathrm{PC} /$ mobile games is enjoyable. \\ FE2: I am absorbed in playing PC/mobile games. \\ FE3: Playing PC/mobile games is exciting. \\ FE4: Playing PC/mobile games entertains me.
}

\section{Perceived control}

PC1: When playing PC/mobile games, I do not feel disturbed.

PC2: When playing PC/mobile games, I strongly feel that I am inside a different world.

PC3: During PC/mobile games, I fully control the games.

Perceived ease of use

PEU1: Playing PC/mobile games does not require a lot of mental effort.

PEU2: I find PC/mobile games easy to play.

PEU3: I find it easy to access and play PC/mobile games when and where I want.

Online social interaction

ON1: I can come in contact with new people online when playing $\mathrm{PC} /$ mobile games.

ON2: Online communication can make me play $\mathrm{PC} /$ mobile games better.

ON3: I can keep in touch with friends in $\mathrm{PC} /$ mobile game who do not meet frequently.

Offline social interaction

OFF1: I like to talk face-to-face when playing this $\mathrm{PC} /$ mobile game.

OFF2: Interacting with people offline when playing this $\mathrm{PC} /$ mobile game makes me interested in what people unlike me are thinking.

OFF3: Interacting with people offline when playing this $\mathrm{PC} /$ mobile game can enhance the friendship in our real life.

Customer engagement

CE1: I am an integrated member of this $\mathrm{PC} /$ mobile game.

CE2: I am an active member of this $\mathrm{PC} /$ mobile game.

CE3: I am a participating member of this $\mathrm{PC} /$ mobile game.

CE4: I am an interacting member of this PC/mobile game.

Continuous playing games intention

$\mathrm{Cl1}$ : I intend to continue playing the $\mathrm{PC} /$ mobile game rather than discontinuance.

$\mathrm{Cl}$ : I intend to continue playing the $\mathrm{PC} /$ mobile $\mathrm{A}$ game rather than other games. 